\title{
Flavone Synthase II (CYP93B) of Antarctic Plant Colobanthus quitensis (Kunth) Bartl.
}

\author{
Rodrigo A. Contreras*, Gustavo E. Zúñiga \\ Laboratory of Plant Physiology and Biotechnology, Department of Biology, Faculty of Chemistry and Biology, University of Santiago, Chile.
}

\section{ARTICLE DETAILS}

\section{Article history:}

Received 19 July 2018

Accepted 01 August 2018

Available online 20 August 2018

\section{Keywords:}

Flavones

Flavone Synthase II

Colobanthus quitensis

Antarctica

\begin{abstract}
A B S T R A C T
The role of flavonoids in plant-environmental stress has many biotechnological applications, in this way Antarctic plants have an important potential for molecular farming. However, the concentration and exploitation of resource are highly restricted, for this reason the use of enzymatic machinery of the Antarctic plants have importance for in vitro flavonoid production for different biotechnological applications. Despite their potential applications, key enzymes for flavonoid biosynthesis are poorly studied in non-model plants. In this work, we studied the flavonoid key enzyme, flavone synthase II (FNS II) in $C$. quitensis. The results show a cooperative kinetic model for NADPH and naringenin. The temperature and $\mathrm{pH}$ stability assays show optimal temperature between $20-30{ }^{\circ} \mathrm{C}$, with an operative range from 2 to $37^{\circ} \mathrm{C}$, pH stability shows an optimum of 7.0 to 8.0, with operative range from 3.0 to 8.0, demonstrating a big thermal and $\mathrm{pH}$-stability, an interesting characteristic to in vitro production of flavones.
\end{abstract}

\section{Introduction}

Plants, as sessile organisms, are constantly subject to environmental changes [1]. For this reason, they have evolved to respond to such adverse conditions by acquiring certain mechanisms; these include responses associated with secondary metabolism [2]. The secondary metabolism of plants presents a wide range of metabolites. By definition, secondary metabolites are not necessary for vital processes in plant metabolism, but provide comparative advantages in competence processes, for instance, plant-plant, plant-insect, plant-microorganism (virus, bacteria and fungus), plant-animal and plant-abiotic interactions [3]. Secondary metabolism involves the biosynthesis of different types of chemical compounds, such as alkaloids (present in around 20 per cent of vascular plants), terpenes (present in all plant genres with lipophilic characteristics), glucosinolates and cyanogens (with a low presence in nature), and phenolic compounds $[4,5]$. Phenolic compounds comprise a wide family of secondary metabolites, with more than 10,000 characterised compounds. They possess chemical heterogeneity and multiple functions in plants with many biotechnological applications, related to defence, mechanical support, photoprotective effects, antioxidants and allelochemicals [6, 7]. The biosynthesis of phenolic compounds is derived from shikimate and chorismate pathways, which provides L-phenylalanine (L-phe). L-phe is the substrate of phenylalanine ammonia-lyase enzyme (PAL), the first and key enzyme of the phenylpropanoid pathway. PAL catalyses the conversion of L-phe to transcinnamic acid, the first secondary metabolite of this pathway. Later, transcinnamic acid is hydroxylated by cinnamate-4-hydroxylase $(\mathrm{C} 4 \mathrm{H})$ in the fourth position, forming $p$-coumaric acid. Subsequently, $p$-coumaric acid is a substrate of $p$-coumaroyl-CoA ligase (4CL), forming $p$-coumaroyl-CoA; the presence of $\mathrm{CoA}$ leaving group is very important for the formation of flavonoids. Chalcones synthase (CHS) catalyses the condensation of $p$ coumaroyl-CoA with 3 malonyl-CoA molecules to give naringeninchalcone, the first flavonoid of the pathway. Naringenin-chalcone is cycled by chalcone isomerase enzyme (CHI), forming the flavanone naringenin. This is a key point, because naringenin is the first flavonoid with the three characteristic rings. Naringenin may be a substrate of several enzymes, and in this work, we will focus on the flavones biosynthesis [8, 9]. Flavones are catalytic products of flavone synthase (FNS); in nature, there are two types of FNS, FNS I and FNS II. FNS I is a dioxygenase that catalyses the desaturation of the $\mathrm{C}$-ring between $\mathrm{C}_{2}-\mathrm{C}_{3}$, forming apigenin from naringenin, using as co-substrate 2-oxoglutarate [10]. This enzyme is

restricted in nature, principally to Apiaceae members, such as parsley [8, 11]. FNS II, widely distributed in nature, is a transmembrane enzyme located in endoplasmic reticulum (ER), part of the cytochrome P450 superfamily (CYP450), subclass 93B (CYP93B), it uses $\mathrm{O}_{2}$ and $\mathrm{NADPH}$ as co-substrate [12]. Flavones possess several functions in plant ecology and physiology: for example, they participate in allelochemical interactions with symbionts (fungus that forms micorhiza and nitrogen-fixing bacteria). In some flowers, they form co-pigments with anthocyanins and expand the colour spectra to attract pollinators; they also have antioxidant properties and UV light absorption capacity $[13,14]$. C. quitensis is a dicot plant belonging to the Caryophyllaceae family. It has been successfully micropropagated in our laboratory [15]. In the present work, considering the normal environmental conditions, we postulate that $C$. quitensis has an efficient and stable FNS II activity with biotechnological projections.

\section{Experimental Methods}

\subsection{Plant Material}

In vitro shoots were generated, as previously described by Zúñiga et al. [15]. The plantlets were growth over one month in a Murashige-Skoog [16] basal media, supplemented with $N^{6}$-benzilaminopurine $(0.3 \mathrm{mg} / \mathrm{L})$ and kinetin $(0.1 \mathrm{mg} / \mathrm{L})$, using $0.2 \%$ of phytagel (Sigma-Aldrich, MO, USA) as gelling agent at $\mathrm{pH} 4.5 \pm 2$, in conservation chambers at $13 \pm 2{ }^{\circ} \mathrm{C}$, with a photoperiod of $16 / 8$ hours light/darkness.

\subsection{Microsome Preparation}

A $2 \mathrm{~g}$ of fresh tissue were grounded in liquid nitrogen to form a fine powder. Subsequently, the method of Bafor et al. [17] was used. The fine powder was resuspended in $10 \mathrm{~mL}$ of buffer potassium phosphate $(0.1 \mathrm{M}$, $\mathrm{pH}$ 7.2) containing $0.1 \% \mathrm{BSA}, 1000 \mathrm{U} / \mathrm{mL}$ of catalase, $0.33 \mathrm{M}$ sucrose; the suspension was filtered using double miracloth, and the filtered extract was diluted tenfold in the same buffer. The resultant solution was centrifuged at $20000 \mathrm{~g}$ for $10 \mathrm{~min}$. The supernatant was filtered in miracloth and the filtrate was ultracentifuged at $105000 \mathrm{~g}$ for $90 \mathrm{~min}$. Finally, the pellet was resuspended in one volume of potassium phosphate buffer $(0.1 \mathrm{M}, \mathrm{pH} 7.2)$ containing $0.1 \% \mathrm{BSA}$ and $1000 \mathrm{U} / \mathrm{mL}$ of catalase. The protein content was determined using BCA kit assay using the resuspension buffer as a blank (Thermo Scientific, USA).

\subsection{Enzymatic Assay for FNS II}

We used the methodology of Zhang et al. [13]. A sample mixture contains a final concentration of potassium phosphate buffer $(80 \mathrm{mM}, \mathrm{pH}$ 
8.0), $0.5 \mathrm{mM} \mathrm{GSH}$, naringenin and NADPH at different concentrations. Naringenin dependence assay was charged, using a fixed concentration of NADPH $(0.4 \mathrm{mM})$ and $0-0.35 \mathrm{mM}$ of naringenin. NADPH dependence assay was charged, using a fixed concentration of naringenin $(0.1 \mathrm{mM})$ and $0-$ $0.9 \mathrm{mM}$. For kinetic of decomposition of NADPH in time, we used the concentrations of $0.4 \mathrm{mM}$ of NADPH and $0.1 \mathrm{mM}$ of naringenin. The enzyme activity was expressed in terms of NADPH consumption at $340 \mathrm{~nm}$ and the assay was carried out at $25{ }^{\circ} \mathrm{C}$, using the first point of curve as a blank. The naringenin consumption and apigenin production was carried out using HPLC with diode array detector (DAD) (Agilent 1100 series, Palo Alto, CA). Mobile phases were compounded of $1 \% \mathrm{v} / \mathrm{v}$ of phosphoric acid (A) and acetonitrile (B) in gradient, 0 min, $10 \%$ of B, 5 min, $25 \%$ of B, 8 min, $35 \%$ of B, $15 \mathrm{~min}, 60 \%$ of B, $17 \mathrm{~min}, 35 \%$ of B and finally $20 \mathrm{~min}, 10 \%$ of B, using a RP-C18 column (Zorbax, Eclipse XDB-C18, 4.6 x $150 \mathrm{~mm}, 5$ $\mu \mathrm{m})$. The flow rate was $1 \mathrm{~mL} / \mathrm{min}$ and the column were thermostatically controlled at $25^{\circ} \mathrm{C}$. UV-detection was performed at $280 \mathrm{~nm}$.

\subsection{Effect of Temperature and $p H$ on FNS II Activity}

To determinate temperature stability, the assays were carried out as previously described using a thermostatically controlled block, samples was collected at $0,2,4,12,25,30,37,52$ and $100^{\circ} \mathrm{C}$; $\mathrm{pH}$ dependence assays were carried out using different buffers, for acidic range we used Tris-HCl $(50 \mathrm{mM}, \mathrm{pH} 1.0,3.0$ and 5.0). For basic range we used potassium phosphate buffer (80 mM, pH 7.0, 8.0, 10.0 and 12.0).

\subsection{Statistical Analysis}

For determination of kinetic parameters, we used the software Graphpad Prism 5.0. All analysis was analysed using ANOVA $(\mathrm{P}<0.05)$ in triplicated.

\section{Results and Discussion}

\subsection{Kinetic Properties}

We analysed the NADPH and naringenin consumption, first measure in the time at $340 \mathrm{~nm}$ in spectrophotometer (Fig. 1A), and observed a sigmoidal pattern. Monitoring the naringenin consumption and apigenin apparition using HPLC-DAD (Fig. 1B), this result permitted the election of 20 min of reaction time to obtain $\mathrm{V}_{0}$. In the second stage, we analysed the dependence of NADPH and naringenin concentrations in an $\mathrm{O}_{2}$ atmosphere; for both substrates, the fit patterns are sigmoidal (Fig. 2), and represent a typical cooperatively kinetic. Hill adjustment is based on Eq.(1),

$$
V_{0}=\frac{V_{\max }[S]^{h}}{K^{\prime}+[S]^{h}}
$$

Using this adjustment, we obtained the kinetic parameters, which are presented in Table 1. The Hill number is two and the inverse-reciprocal plot shows a quadratic pattern (Fig. 2B and 2E), consistent with the Hill number calculation for this enzyme. Using Eq.(2), we obtained the slope of the curves that represents $-h$ (Hill number) (Fig. 2C and 2F).

$$
\log \left[\frac{V_{\max }}{V_{0}}-1\right]=\log \left(K^{\prime}\right)-h \log [S]
$$
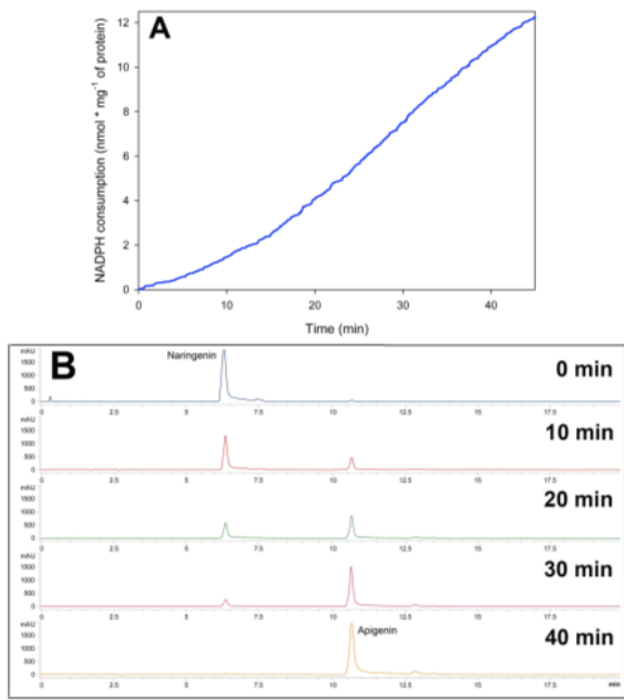

Fig. 1 NADPH and naringenin consumption in the time. (A) represents the NADPH consumption in kinetics at $340 \mathrm{~nm}$ in spectrophotometer and (B) represents the naringenin consumption and apigenin apparition in the time, measured by HPLC$\mathrm{DAD}$ at $280 \mathrm{~nm}$

https://doi.org/10.30799/jnpr.067.18040206
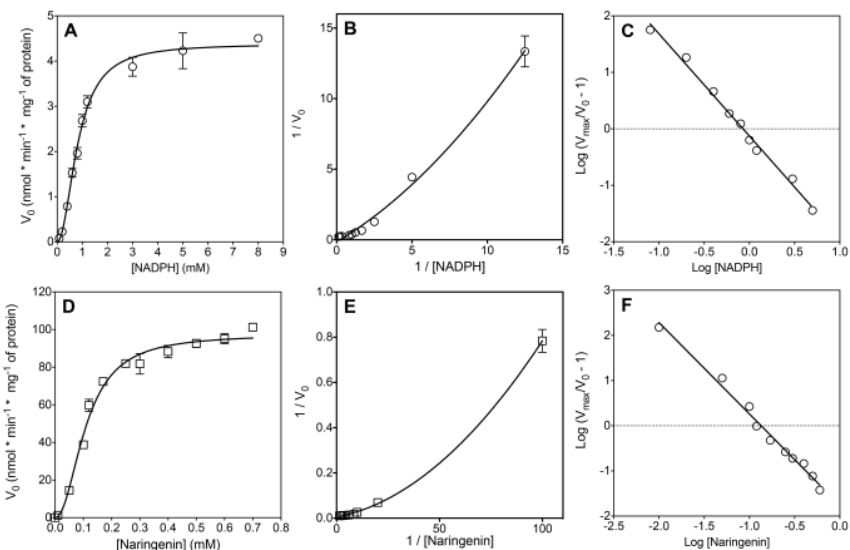

Fig. 2 Enzyme dependence of NADPH and naringenin. A represents a dependence of $\mathrm{NADPH}, \mathrm{B}$ the inverse-reciprocal plot and $\mathrm{C}$ the plot based in equation II for NADPH. $D$ represents the dependence of naringenin, $E$ the inverse-reciprocal plot and $F$ the plot based on equation II for naringenin. Each point represents a mean of three independent measures \pm standard error.

Table 1 Kinetic parameters for FNS II from C. quitensis microsomes. Parameters as adjusted as described in Eqs.(1) and (2)

\begin{tabular}{lllll}
\hline Substrate & $\mathrm{K}^{\prime}(\mu \mathrm{M})$ & $\mathrm{V}_{\max }(\mathrm{nmol} / \mathrm{min} / \mathrm{mg}$ of protein $)$ & $h$ & $\mathrm{R}^{2}$ \\
\hline Naringenin & $9.74 \pm 0.48$ & $97.45 \pm 2.32$ & $2.10 \pm 0.21$ & 0.98 \\
NADPH & $684.00 \pm 78.49$ & $4.38 \pm 0.11$ & $2.03 \pm 0.22$ & 0.99 \\
\hline
\end{tabular}

FNS II from $C$. quitensis has two allosteric binding sites to the union of NADPH (in Fe-porphyrin) and for flavanone. The kinetic parameters and fit reveal that FNS II from $C$. quitensis is a cooperative enzyme, the analysis from $\mathrm{K}^{\prime}$ reveals that limit substrate is NADPH and correlates with the physiological roles of $\mathrm{NADPH}$, because is a limiting factor in the biochemical phase of photosynthesis [18] and in the Halliwell-Asada cycle [19], revealing a possible role of antioxidant status in the synthesis of flavones, the proposed mechanism is the reduction of Fe-porphyrin by NADPH as a first step, and in second the entrance of naringenin to produce apigenin (Fig. 3).

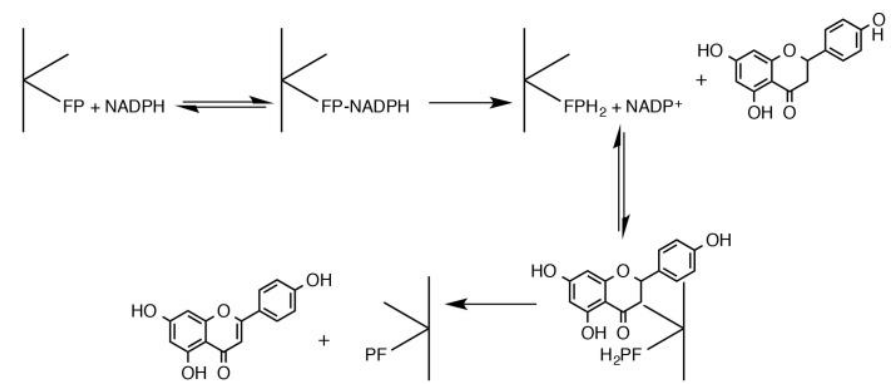

Fig. 3 Model of catalytic mechanism for FNS II of C. quitensis

\subsection{Temperature and $p H$ Stability}

The temperature stability analysis reveals a wide range of operating temperatures (Fig. 4a), with an operative range from 2 to $37{ }^{\circ} \mathrm{C}$ with optimal at 12 to $30^{\circ} \mathrm{C}$, another characterized FNS II from Gerbera [20] and Glycine $\max$ [12] has not been characterized in thermal stability. pH shows a similar comportment (Fig. 4b), with a wide range of operative $\mathrm{pH}$, although it was see the optimal catalytic $\mathrm{pH}$ is 7.0 to 8.0, FNS II shows more stability at acidic pH (the enzyme is operative from $\mathrm{pH} 3.0$ to 8.0), this is concordant with the previously described [15] that discussed that the optimal in vitro growth of $C$. quitensis is $\mathrm{pH} 4.5$.
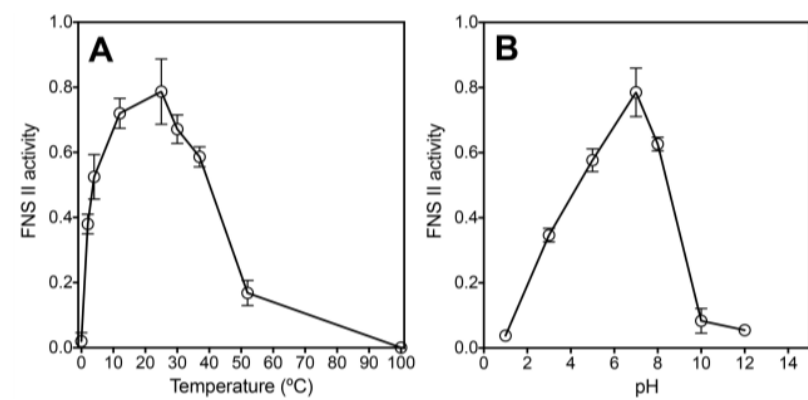

Fig. 4 Thermal and pH stability of FNS II. A represents the thermal stability and B pH stability. In both cases, the relative activity was represented in function of optimal note the wide range of operative catalysis. 


\section{Conclusion}

This is the first study of catalytic properties and stability of FNS II from Antarctic C. quitensis. The kinetic studies reveal that NADPH is the limiting substrate and the high affinity of enzyme for naringenin. Moreover, the enzyme shows a wide range of thermic and $\mathrm{pH}$ stability, suggested in the fact that $C$. quitensis is an adapted plant to Antarctic environment, a very inhospitable niche for plants. For further work, we project the production of bioactive compounds in vitro using microsomes of $C$. quitensis, for evaluation of different biological activities.

\section{Acknowledgment}

Financed by Conicyt, doctoral fellowship (RAC), projects AT24120963, Fondecyt 3160274 (RAC) and project Fondecyt 1140189 (GEZ). The authors thank CEDENNA and Project Fortalecimiento Usach USA1799_ZG203516. Acknowledgements to Chilean Antarctic Institute (INACH) by logistics in sample collection.

\section{References}

[1] R.M. Borges, Plasticity comparisons between plants and animals, Plant Signal. Behav. 3(6) (2008) 367-375.

[2] R.A. Dixon, N.L. Paiva, Stress-induced phenylpropanoid metabolism, Plant Cell 7(7) (1995) 1085-1097.

[3] M, Petersen, J. Hans, U. Matern, Biosynthesis of phenylpropanoids and related compounds, in annual plant reviews, Biochem. Plant Second. Metabol. 40 (2010) 182-257.

[4] F. Bourgaud, A. Hehn, R. Larbat, S. Doerper, E. Gontier, S. Kellner, U. Matern, Biosynthesis of coumarins in plants: a major pathway still to be unravelled for cytochrome P450 enzymes, Phytochem. Rev. 5(2-3) (2006) 293-308.

[5] K. Hahlbrock, D. Scheel, Physiology and molecular biology of phenylpropanoid metabolism, Annu. Rev. Plant Physiol. Plant Molec. Biol. 40(1) (1989) 347-369.
[6] J.B. Harborne, C.A. Williams, Advances in flavonoid research since 1992, Phytochem. 55(6) (2000) 481-504.

[7] M. López, F. Martínez, C. Del Valle, M. Ferrit, R. Luque, Study of phenolic compounds as natural antioxidants by a fluorescence method, Talanta 60(2-3) (2003) 609-616.

[8] S. Martens, G. Forkmann, U. Matern, R. Lukačin, Cloning of parsley flavone synthase I, Phytochem. 58(1) (2001) 43-46.

[9] H.A. Stafford, Flavonoid evolution: An enzymic approach, Plant Physiol. 96(3) (1991) 680-685.

[10] L. Britsch, Purification and characterization of flavone synthase I, a 2oxoglutarate-dependent desaturase, Arch. Biochem. Biophys. 282(1) (1990) 152-160.

[11] S. Martens, A. Mithöfer, Flavones and flavone synthases, Phytochem. 66(20) (2005) 2399-2407.

[12] J. Fliegmann, K. Furtwängler, G. Malterer, C. Cantarello, G. Schüler, J. Ebel, A. Mithöfer, Flavone synthase II (CYP93B16) from soybean (Glycine max L.), Phytochem. 71(5-6) (2010) 508-514.

[13] J. Zhang, S. Subramanian, Y. Zhang, O. Yu, Flavone synthases from Medicago truncatula are flavanone-2-hydroxylases and are important for nodulation, Plant Physiol. 144(2) (2007) 741-751.

[14] J.F. Bornman, New trends in photobiology: Target sites of UV-B radiation in photosynthesis of higher plants, J. Photochem. Photobiol. B: Biol. 4(2) (1989) 145-158.

[15] G.E. Zúñiga, P. Zamora, M. Ortega, A. Obrecht, Short Note: Micropropagation of antarctic Colobanthus quitensis, Antarct. Sci. 21(02) (2009) 149-150.

[16] T. Murashige, F. Skoog, A revised medium for rapid growth and bio assays with tobacco tissue cultures. Physiol. Plant. 15(3) (1962) 473-497.

[17] M, Bafor, M.A. Smith, L. Jonsson, K. Stobart, S. Stymne, Ricinoleic acid biosynthesis and triacylglycerol assembly in microsomal preparations from developing castor-bean (Ricinus communis) endosperm, Biochem. J. 280(2) (1991) 507-514.

[18] G. Forti, A. Furia, P. Bombelli, G. Finazzi, In vivo changes of the oxidationreduction state of NADP and of the ATP/ADP cellular ratio linked to the photosynthetic activity in Chlamydomonas reinhardtii, Plant Physiol. 132(3) (2003) 1464-1474.

[19] C.H. Foyer, G. Noctor, Ascorbate and glutathione: The heart of the redox hub Plant Physiol. 155(1) (2011) 2-18.

[20] S. Martens, G. Forkmann, Cloning and expression of flavone synthase II from Gerbera hybrids, Plant J. 20(5) (1999) 611-618. 